\title{
Fabrikasi dan Karakterisasi Directional Coupler Konfigurasi $3 \times 3$ Susunan Segitiga Berbahan Serat Optik Plastik Step Index Multimode Tipe FD-620-10
}

\author{
Ning Rosianah dan Gontjang Praji \\ Jurusan Fisika, Fakultas Matematika dan Ilmu Alam, Institut Teknologi Sepuluh Nopember (ITS) \\ Jl. Arief Rahman Hakim, Surabaya 60111 Indonesia \\ e-mail: gontjang@physics.its.ac.id
}

\begin{abstract}
Abstrak-Dalam penelitian ini telah dilakukan fabrikasi dan karakterisasi directional coupler konfigurasi $3 \times 3$ susunan segitiga berbahan serat optik plastik step index multimode tipe FD-620-10 dengan panjang kupasan $35 \mathrm{~mm}$, $40 \mathrm{~mm}, 45 \mathrm{~mm}, 50 \mathrm{~mm}, 55 \mathrm{~mm}$, dan $60 \mathrm{~mm}$ menggunakan pendekatan metode Fused Biconical Tapered (FBT). Hasil karakterisasi directional coupler menggunakan BF5R-D1-N diperoleh bahwa panjang kupasan $45 \mathrm{~mm}$ dengan input pada port A1 menunjukkan nilai coupling ratio $\mathrm{CR}=\mathbf{0 , 6}$; 0,$2 ; 0,2$ dan excess loss $\mathrm{Le}=-7,76 \mathrm{~dB}$, pada port $\mathrm{B} 1$ menunjukkan nilai $\mathrm{CR}=0,2 ; 0,6 ; 0,2$ dan $\mathrm{Le}=-6,76 \mathrm{~dB}$, pada port $\mathrm{C1}$ menunjukkan nilai $\mathrm{CR}=0,2 ; 0,19 ; 0,61$ dan Le $=-6,75 \mathrm{~dB}$. Directional coupler ini paling baik digunakan sebagai piranti dalam sensor.
\end{abstract}

Kata Kunci-Directional Coupler, Fabrikasi, Karakterisasi, Segitiga.

\section{Pendahuluan}

Cerat optik merupakan media transmisi atau pandu $\checkmark$ gelombang cahaya berbentuk silinder yang dikembangkan di akhir tahun 1960-an dalam sistem komunikasi yang semakin lama membutuhkan bandwidh yang besar dengan laju transmisi yang tinggi [1]. Pada umumnya, serat optik terdiri dari tiga bagian yaitu inti (core), kulit (cladding), dan jaket (coating). Berdasarkan struktur dan sifat transmisinya, serat optik dapat diklasifikasikan menjadi dua yaitu serat optik moda tunggal (singlemode) dan serat optik moda jamak (multimode) [2]. Berdasarkan penjalaran gelombang yang melalui inti, serat optik terbagi menjadi dua macam, yaitu serat optik step index dan serat optik graded index. Pada dasarnya cahaya disebarkan melalui core dengan cara pemantulan dalam total [3].

Dalam perkembangannya, serat optik tidak hanya berfungsi untuk mentransmisikan informasi tetapi juga berkembang menjadi piranti optik dengan fungsi yang lebih luas. Piranti optik tersebut dapat berbentuk coupler dengan berbagai macam variasinya. Coupler merupakan piranti optik pasif yang berfungsi sebagai penggabung dua atau lebih panjang gelombang atau sinyal menjadi dua atau lebih. Directional coupler termasuk coupler yang paling dikembangkan. Terdapat beberapa metode pembuatan directional coupler berbahan serat optik plastik, di antaranya metode fused biconical tapered $(F B T)$, yaitu dengan menggabungkan sejumlah serat optik pada panjang kopling tertentu sehingga menjadi directional coupler dengan N-port [4].
Penelitian mengenai directional coupler di Indonesia yaitu fabrikasi directional coupler konfigurasi $3 \times 3$ serat optik plastik step index multimode tipe FD-620-10 susunan planar dengan metode fused biconical tapered $(F B T)$. Dihasilkan directional coupler dengan coupling ratio yang paling baik sebesar 0,345 pada panjang interaksi kopling $60 \mathrm{~mm}$ [5]. Pada proses fabrikasi directional coupler $3 \times 3$, terdapat dua tipe struktur yang sering digunakan, yaitu susunan segitiga dan planar [6].

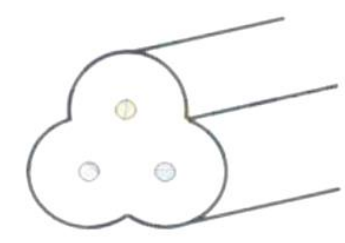

(a)

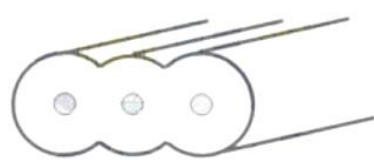

(b)
Gambar 1. Dua Tipe Konfigurasi Coupler 3×3: (a) Segitiga dan (b) Planar [6]

Dalam penelitian ini, directional coupler konfigurasi $3 \times 3$ difabrikasi dengan susunan segitiga menggunakan serat optik plastik step index multimode tipe FD-620-10 dengan pendekatan metode fused biconical tapered (FBT) pada variasi panjang kupasan $35 \mathrm{~mm}, 40 \mathrm{~mm}, 45$ $\mathrm{mm}, 50 \mathrm{~mm}$, $55 \mathrm{~mm}$, dan $60 \mathrm{~mm}$. kemudian dapat diketahui hasil karakterisasi directional coupler konfigurasi $3 \times 3$ susunan segitiga menggunakan BF5RD1-N.

Parameter-parameter pokok directional coupler antara lain:

Coupling ratio $(C R)$, yaitu proporsi daya masukan pada masing-masing keluaran [7].

$C R=\frac{P_{A 2}}{\left(P_{A 2}+P_{B 2}+P_{C 2}\right)}$

Exceess loss $\left(L_{e}\right)$, yaitu rugi daya total [7].

$L_{e}=10 \log \left(\frac{\sum P_{j}}{p_{i}}\right) d B=10 \log \left(\frac{P_{A 2}+P_{B 2}+P_{C 2}}{P_{A 1}}\right) d B$

\section{MetOdOLOGI}

\section{A. Tahap Fabrikasi}

Prosedur fabrikasi directional coupler mengikuti langkah-langkah sebagai berikut:

1) Pemotongan serat optik

Serat optik dipotong menggunakan alat pemotong sepanjang $20 \mathrm{~cm}$ sebanyak tiga buah. Untuk memudahkan identifikasi, ketiga serat optik diberi label A, B, dan C. 


\section{2) Pengupasan coating dan cladding}

Dengan bantuan alat pengupas, serat optik yang akan dikupas ditempatkan di tengah-tengah bagian alat tersebut pada keadaan lurus dan sejajar, kemudian ditempelkan selotip pada kedua ujung agar tidak geser. Selanjutnya serat optik dikupas dengan panjang kupasan $35 \mathrm{~mm}, 40 \mathrm{~mm}, 45 \mathrm{~mm}, 50 \mathrm{~mm}, 55 \mathrm{~mm}$, dan $60 \mathrm{~mm}$ menggunakan cutter.

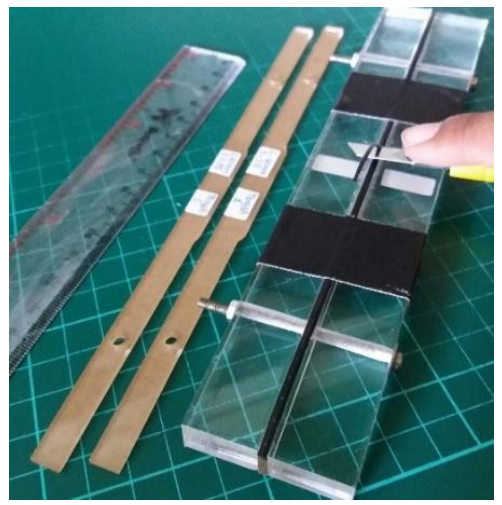

Gambar 2. Proses Pengupasan Coating

Selanjutnya, serat optik diletakkan pada alat pemoles. Seperti pada tahap sebelumnya, serat optik harus pada keadaan lurus dan sejajar. Kemudian dengan menggunakan ampelas, serat optik digosok searah. Ampelas yang digunakan yaitu dengan mesh 360, 1200, 1500, dan 2000. Selanjutnya setiap bagian yang dipoles dibersihkan menggunakan alkohol 70\% dan dikeringkan.

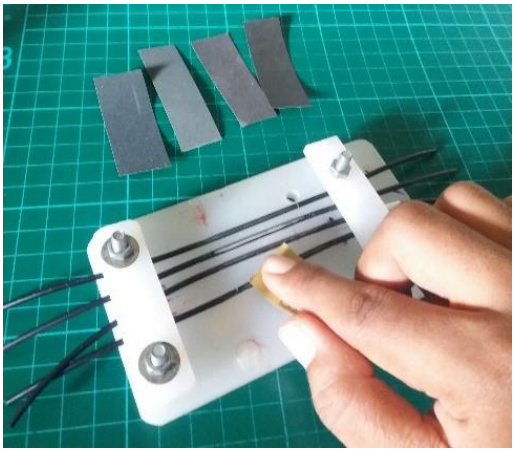

Gambar 3. Proses Pemolesan

3) Uji kerataan

Serat optik yang telah dikupas dan dipoles diuji kerataanya untuk mengetahui hasil dari pengupasan dan pemolesan yang telah dilakukan. Uji kerataan dilakukan dengan cara melihat bagian kupasan serat optik pada setiap port dan seluruh variasi panjang kupasan. Pengujian dilakukan dengan menggunakan Stereo Microscope \#3 - Carl Zeiss Stemi DV4.

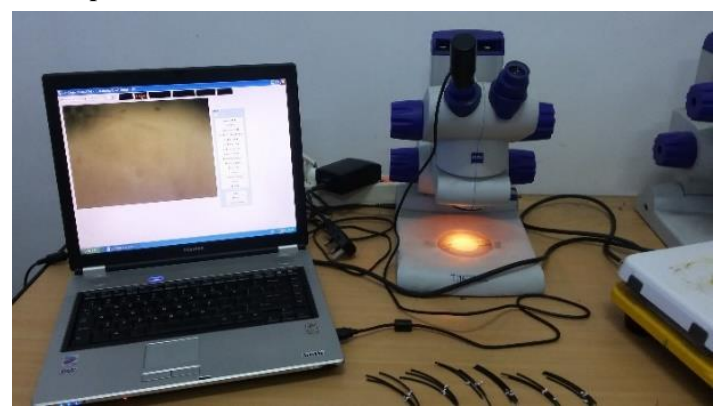

Gambar 4. Proses Uji Kerataan

Agar dapat diketahui bagian yang belum terkupas secara sempurna, maka dilakukan penyinaran pada serat optik menggunakan laser. Pada Gambar 5, bagian yang masih terlihat gelap menandakan bahwa sinar laser belum terhambur keluar. Oleh sebab itu, pada bagian tersebut dilakukan pemolesan ulang.

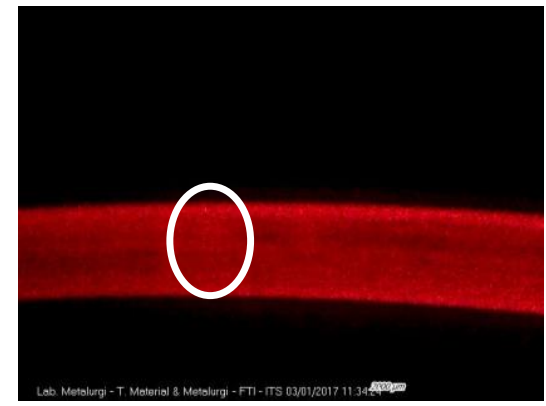

Gambar 5. Panjang Kupasan 45 mm Port A

\section{4) Tahap Penggandengan}

Penggandengan dilakukan dengan cara menggandeng ketiga serat optik pada bagian yang telah dikupas dengan cara diikat menggunakan benang jahit sesuai panjang kupasan. Tahap ini harus dilakukan dengan perlahan dan diusahakan ketiga bagian benar-benar matching.
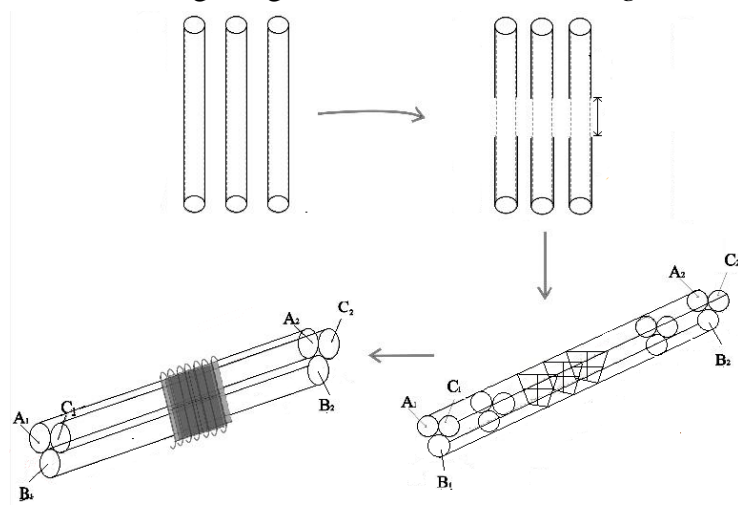

Gambar 6. Tahap Penggandengan Directional Coupler

\section{B. Tahap Karakterisasi}

Karakterisasi directional coupler hasil fabrikasi menggunakan BF5R-D1-N. Karakterisasi ini bertujuan untuk memperoleh nilai coupling ratio $(C R)$ dan excess loss (Le). Sensor ini merupakan sensor khusus untuk menganalisis daya keluaran yang diterima oleh serat optik. Pengukuran dilakukan sebanyak 20 kali pengulangan pada masing-masing port.

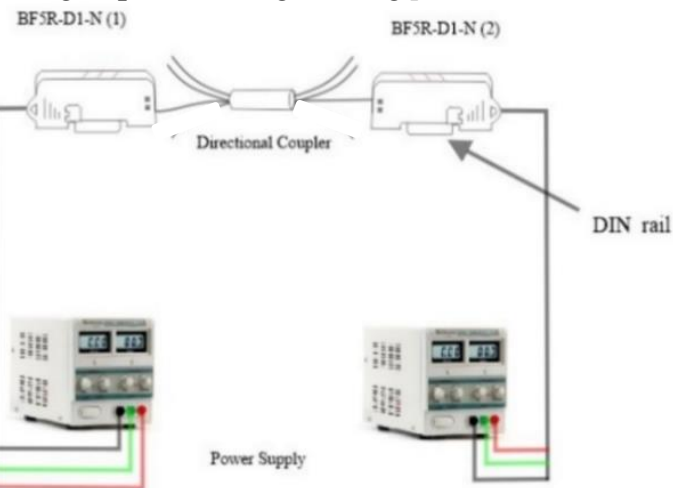

Gambar 7. Set Up Alat pada Proses Karakterisasi Directional Coupler

\section{HASIL DAN PEMBAHASAN}

Pada penelitian ini, directional coupler difabrikasi sebanyak enam buah dengan susunan segitiga. Fabrikasi directional coupler konfigurasi $3 \times 3$ menggunakan metode fused biconical tapered (FBT) dilakukan dengan mengupas tiga serat optik dengan panjang kupasan 35 $\mathrm{mm}, 40 \mathrm{~mm}, 45 \mathrm{~mm}, 50 \mathrm{~mm}, 55 \mathrm{~mm}$, dan $60 \mathrm{~mm}$. 


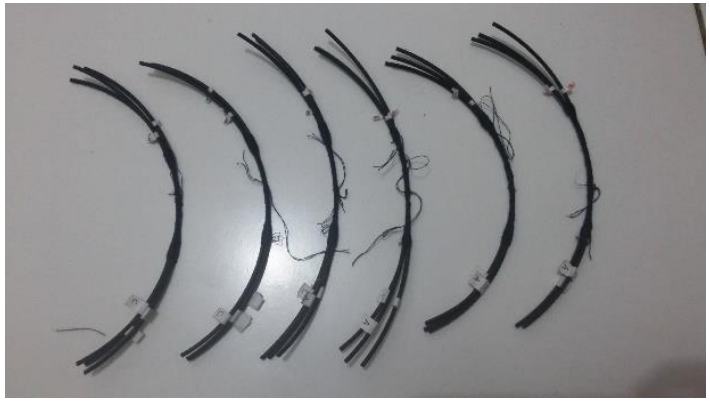

Gambar 8. Hasil Fabrikasi Directional Coupler

Pada proses fabrikasi directional coupler konfigurasi $3 \times 3$ susunan segitiga, ketiga serat optik dikupas seluruh sisinya pada bagian coating hingga menyisakan bagian core. Walaupun ketiga serat optik dikupas seluruh bagian, namun intensitas cahaya yang melewatinya berbeda. Hal ini dikarenakan cahaya yang terpandu di dalam serat optik lebih dominan melewati sumbu serat optik daripada melewati tepinya. Selain itu, faktor ketebalan serat optik sangat berpengaruh pada directional coupler. Proses pemolesan yang tidak sama antara serat optik satu dengan lainnya mengakibatkan acuan untuk mendapatkan bagian core juga berbeda antara satu dengan lainnya. Pemantulan dalam total belum dapat terjadi secara sempurna, dikarenakan tidak ada pengganti bagian cladding pada daerah selain kopling yang digandeng. Sehingga intensitas cahaya yang melewati port input lebih tinggi daripada dua port lain.

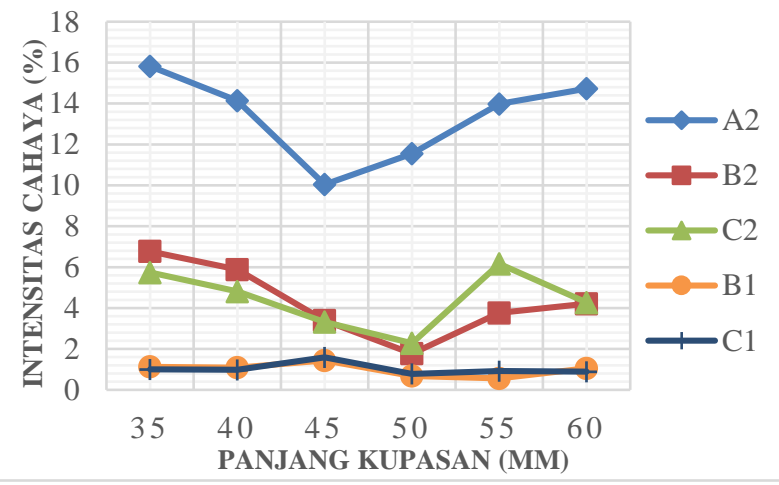

Gambar 9. Grafik Pengaruh Panjang Kupasan Terhadap Prosentase Intensitas Cahaya pada Tiap Output dengan Port A1 Sebagai Input

Pada Gambar 9, port A2 memiliki intensitas yang jauh lebih tinggi daripada port B2 dan C2. Hal ini dikarenakan susunan directional coupler yang berbentuk segitiga. Ketika diberikan input pada port A1, maka cahaya akan cenderung melewati sumbu serat optik A2. Sedangkan cahaya yang berpindah ke port B2 dan C2 memiliki intensitas dengan selisih yang jauh dari intensitas port A2. Hal ini dikarenakan adanya celah kosong atau gap yang berada di tengah kopling. Serat optik dikupas pada bagian coating dan cladding hingga tersisa bagian core saja. Bagian core yang terkupas ini digabung dengan core serat optik lainnya, sehingga gap atau celah antar core yang terbentuk besar pada bagian tengah directional coupler. Jika dilihat dari penjalaran cahaya, directional coupler susunan segitiga ini memiliki lebar lintasan perambatan cahaya yang sama. Misalnya pada directional coupler dengan panjang kupasan $45 \mathrm{~mm}$ dengan port input A1, maka moda orde tinggi dari port input A1 akan berpindah ke dua sisi port output yang lain, B2 dan C2 secara hampir sama. Sedangkan pada port output $\mathrm{A} 2$ memiliki intensitas yang jauh lebih tinggi daripada port B2 dan C2. Hal ini dikarenakan moda orde rendah tetap terpandu pada serat optik awal. Proses perpindahan daya gelombang optik ini sesuai dengan teori moda terkopel. Kebocoran gelombang juga bertambah besar seiring dengan bertambahnya panjang kupasan. Semakin besar panjang kupasan, maka nilai intensitas cahaya akan semakin kecil yang berarti bahwa rugi daya semakin bertambah besar.

Faktor lain yang menyebabkan rugi daya yang besar adalah daerah antar core yang berinteraksi langsung di dalam directional coupler lebih kecil daripada daerah yang berinteraksi langsung dengan benang jahit. Hal ini menyebabkan sebagian besar intensitas cahaya diserap oleh benang jahit atau terhambur keluar melewati celahcelah benang jahit. Selain itu, pemantulan dalam total yang terjadi di dalam directional coupler juga belum terjadi secara sempurna sehingga masih terdapat cahaya yang terhambur keluar. Hal ini terjadi pada saat pemasangan serat optik pada BF5R-D1-N kurang tepat pada saat dilakukan karakterisasi. Pemasangan serat optik pada BF5R-D1-N yang kurang tepat mengakibatkan sudut sinar datang kurang dari sudut kritis yang menyebabkan cahaya tidak hanya dipantulkan, melainkan juga dibiaskan keluar dari directional coupler.

Hasil fabrikasi directional coupler konfigurasi $3 \times 3$ susunan segitiga memiliki loss atau rugi daya yang besar, hal ini dikarenakan bagian core juga terkupas sehingga core tidak lagi berbentuk silinder utuh, melainkan silinder pipih. Proses ini yang menyebabkan rugi daya serat optik cukup besar. Perbedaan nilai intensitas cahaya dapat menyebabkan parameter-parameter directional coupler seperi CR (coupling ratio) dan Le (excess loss) juga berbeda. Perbedaan nilai-nilai tersebut salah satunya disebabkan oleh ketidaksimetrian sepanjang daerah kupasan dan daerah ujung pengupasan antara ketiga serat optik pada saat proses pengupasan dan penggandengan. Ketidaksimetrian terjadi akibat struktur permukaan serat optik hasil pengupasan yang tidak rata dan ketebalan kupasan yang berbeda serta panjang kupasan yang tidak sama (dalam orde mikro) untuk tiap serat optik yang digandeng. Hal ini dikarenakan daerah kerja pada serat optik dalam orde nano (panjang gelombang), sedangkan fabrikasi yang dilakukan secara konvensional dengan pengukuran menggunakan orde mili.

TABEL 1. KARAKTERISTIK DIRECTIONAL COUPLER DENGAN PANJANG

\begin{tabular}{ccc}
\multicolumn{3}{c}{ KUPASAN 45 MM } \\
\hline \hline Input & $C R$ & Le $(\mathrm{dB})$ \\
\hline \multirow{3}{*}{ A1 } & 0,60 & \\
& 0,20 & $-7,76$ \\
& 0,20 & \\
\hline \multirow{3}{*}{ B1 } & 0,20 & \\
& 0,60 & $-6,76$ \\
& 0,20 & \\
\hline \multirow{3}{*}{ C1 } & 0,20 & \\
& 0,19 & $-6,75$ \\
\hline \hline
\end{tabular}

Nilai coupling ratio $(\mathrm{CR})$ directional coupler yang ditampilkan pada Tabel 1 memperlihatkan bahwa nilai intensitas cahaya pada directional coupler terbagi rata di dua port keluaran serat optik yang lain pada panjang kupasan $45 \mathrm{~mm}$. Karakteristik directional coupler panjang kupasan $45 \mathrm{~mm}$ dengan input pada port A1 
menunjukkan nilai coupling ratio $\mathrm{CR}=0,6 ; 0,2 ; 0,2$ dan excess loss $\mathrm{Le}=-7,76 \mathrm{~dB}$, pada port $\mathrm{B} 1$ menunjukkan nilai $\mathrm{CR}=0,2 ; 0,6 ; 0,2 \mathrm{dan} \mathrm{Le}=-6,76 \mathrm{~dB}$, pada port $\mathrm{C} 1$ menunjukkan nilai $\mathrm{CR}=0,2 ; 0,19 ; 0,61$ dan $\mathrm{Le}=-6,75$ dB. Dari hasil karakterisasi menggunakan BF5R-D1-N, dapat disimpulkan bahwa directional coupler konfigurasi $3 \times 3$ susunan segitiga pada panjang kupasan $45 \mathrm{~mm}$ paling baik digunakan sebagai piranti dalam sensor.

\section{KESIMPULAN}

Dari fabrikasi directional coupler konfigurasi $3 \times 3$ susunan segitiga dengan pendekatan metode fused biconical tapered $(F B T)$ dan hasil karakterisasi menggunakan BF5R-D1-N yang telah dilakukan, menunjukkan bahwa panjang kupasan $45 \mathrm{~mm}$ dengan input pada port $\mathrm{A} 1$ memiliki nilai coupling ratio $\mathrm{CR}=$ 0,60; 0,20; 0,20 dan excess loss $\mathrm{Le}=-7,76 \mathrm{~dB}$, pada port $\mathrm{B} 1$ memiliki nilai $\mathrm{CR}=0,20 ; 0,60 ; 0,20$ dan $\mathrm{Le}=-6,76$ $\mathrm{dB}$, dan pada port $\mathrm{C} 1$ memiliki nilai $\mathrm{CR}=0,20 ; 0,19$; 0,61 dan $\mathrm{Le}=-6,75 \mathrm{~dB}$. Directional coupler ini paling baik digunakan sebagai piranti dalam sensor.

\section{UCAPAN TERIMA KASIH}

Penulis mengucapkan terima kasih kepada Kementerian Riset Teknologi dan Pendidikan Tinggi Republik Indonesia yang telah memberikan dukungan finansial melalui Beasiswa Bidikmisi tahun 2012-2017.

\section{DAFTAR PUSTAKA}

[1] Samian, dkk. 2008."Fabrikasi Directional Coupler Serat Optik Multimode". Jurnal Fisika dan Aplikasinya, Vol. 4 No. 2 Surabaya.

[2] Keiser, Gerd. 1991. Optical Fiber Communications $2^{\text {nd }}$ Edition. New York: McGraw-Hill.

[3] Leno dan Frank. 1993. Introduction to Optics $2^{\text {nd }}$ Edition. United States America: Prentice-Hall.

[4] Sekartedjo, dkk. 2007. Study of Switching Characteristics in Directional Coupler. International Symposium of Modern Optics and Its Applications (ISMOA), Department of Physics ITB August 6-10 2007, Bandung.

[5] Yaqin, Mohammad Ainul. 2015. "Fabrikasi dan Karakterisasi Directional Coupler Konfigurasi $3 \times 3$ Planar Berbahan Serat Optik Plastik Step-Index Moda Jamak Tipe FD-620-10”. Jurnal Sains dan Seni POMITS, Vol. 1 No. 2 Surabaya.

[6] Fang, Zujie, et. all. 2012. Fundamentals of Optical Fiber Sensors. New York: John Wiley \& Sons.

[7] Crisp, J. 2001. Introduction to Fiber Optics $2^{\text {nd }}$ Edition. Oxford: Jordan Hill. 